BMJ Open

Diabetes

Research

\& Care

\section{Aflibercept ameliorates retinal pericyte loss and restores perfusion in streptozotocin-induced diabetic mice}

To cite: Seo EJ, Choi JA, Koh J-Y, et al. Aflibercept ameliorates retinal pericyte loss and restores perfusion in streptozotocin-induced diabetic mice. BMJ Open Diab Res Care 2020;8:e001278. doi:10.1136/ bmjdrc-2020-001278

- Supplemental material is published online only. To view, please visit the journal online (http://dx.doi.org/10.1136/ bmjdrc-2020-001278).

EJS and JAC contributed equally.

$\mathrm{J}-\mathrm{YK}$ and YHY contributed equally.

Part of this study was presented as a poster at the Annual Meeting of the Association for Research in Vision and Ophthalmology, Vancouver, British Columbia, Canada, April 28-May 2, 2019.

Received 14 February 2020 Revised 27 August 2020 Accepted 17 September 2020

Check for updates

C Author(s) (or their employer(s)) 2020. Re-use permitted under CC BY-NC. No commercial re-use. See rights and permissions. Published by BMJ.

For numbered affiliations see end of article.

Correspondence to

Dr Jae-Young Koh;

jkko@amc.seoul.kr and Dr

Young Hee Yoon;

yhyoon@amc.seoul.kr

\section{ABSTRACT}

Introduction Anti-vascular endothelial growth factor (VEGF) agents are used worldwide for advanced-stage diabetic retinopathy (DR). In contrast, apart from blood glucose control, there are no specific treatments that can limit the progression of early-stage DR that starts with pericyte loss and the destruction of the blood-retinal barrier. Here, we examined the efficacy of aflibercept, a potent anti-VEGF agent, against early-DR pathologies in a murine model of streptozotocin (STZ)-induced DR.

Research design and methods STZ was intraperitoneally administered in 8-week-old C57BL/6N male mice. After 4 weeks, the mice were divided into aflibercept-treated and saline-treated groups. Eight weeks after the STZ injection, vascular permeability/leakage was measured with fluorescein angiography in live mice. At 4, 6, and 8 weeks after the STZ injection, the eyes were enucleated, flatmounted, and stained for platelet-derived growth factor receptor- $\beta$ to assess pericyte abundance, CD45 to assess leukocyte recruitment, and fluorescein isothiocyanate dextran to assess perfusion. VEGF levels were quantified in each group. The effects of aflibercept on pericyte number, perfusion status, and leukocyte recruitment/accumulation on mice with diabetes retina were evaluated.

Results Our murine model successfully replicated the salient pathologies of DR such as pericytes loss, hyperpermeability, and perfusion blockage. Interestingly, numerous leukocytes and leukocyte clumps were found in diabetic retinal capillaries, especially in the nonperfused border area of the retina, suggesting a possible mechanism for non-perfusion and related pericyte damage. Treatment with aflibercept in mice with diabetes inhibited the upregulation of VEGF and the associated adhesion molecules while reducing the defects in perfusion. Aflibercept also attenuated pericyte loss in the diabetic retina.

Conclusion VEGF inhibition through aflibercept treatment decreased leukocyte recruitment and aggregation, perfusion blockage, retinal hypoperfusion, and hyperpermeability in mice with diabetes and ultimately attenuated pericyte loss. Our findings suggest that antiVEGF strategies may prove useful as possible therapies for limiting the progression of early-stage DR.

\section{INTRODUCTION}

Diabetic retinopathy (DR), a retinal neurodegenerative and microvascular disease, is one of the leading causes of severe but preventable vision loss in the working-age population. ${ }^{1}$

\section{Significance of this study}

What is already known about this subject?

- Aflibercept, a potent antivascular endothelial growth factor (VEGF) agent, is globally used for advancedstage diabetic retinopathy (DR), such as diabetic macular edema.

- Other than blood glucose control, there are no specific treatments that can limit the progression of early-stage DR, which starts with pericyte loss and blood-retinal barrier destruction.

What are the new findings?

- In a streptozotocin-induced diabetic mice model, which mimicked early-stage of DR, recruitment and aggregation of intravascular leukocytes blocked retinal perfusion, and deterioration of pericytes caused vascular leakage from retinal capillaris.

- Intraperitoneal aflibercept could decrease retinal leukocyte recruitment/aggregation, restore retinal peripheral perfusion, and ameliorates retinal pericyte loss in streptozotocin-induced diabetic mice.

How might these results change the focus of research or clinical practice?

- Anti-VEGF strategies may prove useful as possible therapies for limiting the progression of early-stage DR.

Approximately 285 million people worldwide have diabetes, and this number is expected to reach 300 million by $2025 .^{2}$ Retinal neurodegeneration and subsequent microvascular deterioration are the basic pathogenic changes in DR, but their mutual relationship remains elusive. ${ }^{3}$ About one-third of patients with diabetes show signs of DR, and one-third of these patients can be categorized as visionthreatened due to severe non-proliferative diabetic retinopathy (PDR), PDR, or diabetic macular edema (DME). ${ }^{4} \mathrm{PDR}$ and DME, which are the major complications of DR, can both lead to severe visual impairment. For several decades, the gold standard for the management of advanced DR has been laser photocoagulation; however, recent reports have shown that intravitreal injection of 
antivascular endothelial growth factor (VEGF) agents is highly effective in ameliorating $\mathrm{DME}^{6}$ and is hence being widely used currently.

The worldwide increase in the use of anti-VEGF agents against DR has ushered in the so-called anti-VEGF era. Among the anti-VEGF agents, the fusion protein aflibercept stands out due to its higher binding affinity for VEGF. $^{7}$ Aflibercept is a soluble VEGF decoy receptor generated with the trap technology and binds several members of the VEGF family: VEGF-A, VEGF-B and placental growth factor (PlGF), which activate the VEGF receptor-1 (VEGFR-1). Therefore, aflibercept can further inhibit VEGFR-1 signaling by trapping the PIGF ligand. The signaling pathway of VEGFR-1 modulates vascular development, angiogenesis, cell survival, inflammation, and chemotaxis of inflammatory cells. However, current clinical indications for aflibercept are mainly limited to advanced-stage diseases such as severe DME, which is characterized by leakage from the capillary endothelium. Prior to the development of vascular proliferation or widespread non-perfusion, blood glucose control was considered the only measure for delaying the progression of DR to advanced stages. However, several recent clinical trials have shown that anti-VEGF agents, including aflibercept, are highly effective at improving not only DME but also the Diabetic Retinopathy Severity Scale (DRSS) scores or retinal non-perfusion, a condition mainly involving the microvasculature ${ }^{68-11}$ thus suggesting the possibility that aflibercept may exert beneficial effects on microvascular structures such as retinal endothelial cells or pericytes. Recently, it has been demonstrated that aflibercept regulates retinal inflammation elicited by high glucose via the PIGF/extracellular signal-regulated kinase pathway, and the effects of anti-VEGF agents such as aflibercept are related to molecular interactions and stabilizing energy. ${ }^{12} 13$ If the DR pathogenic cascade could be impeded earlier before the degree of vascular destruction becomes irreversible, more viable vessels can be salvaged and can halt the progression to advanced stages.

Recent pieces of evidence suggested that the primary diabetic retinal manifestation is neurodegeneration. ${ }^{3} 14$ Then, the early stages of vasculopathic DR likely start with a loss of retinal pericytes and consequent disruption of the blood-retinal barrier (BRB), which then gradually leads to retinal capillary hyperpermeability and occlusion. ${ }^{15} 16$ Since pericytes are located adjacent to blood vessels and regulate endothelial cell properties and contribute to the stability and maintenance of blood vessels, the loss of retinal pericytes is considered to play a critical role in the early pathogenesis of DR. ${ }^{17-19}$ Pericyte loss has also been experimentally observed as an initial structural change in DR using streptozotocin (STZ)-induced murine model of diabetes. ${ }^{20} 21$

Together with pericyte loss, retinal inflammation has also been highlighted as a contributing factor to the pathology of DR. Inflammatory changes associated with DR include increased inflammatory cytokine expression, macrophage infiltration, leukocyte adhesion and infiltration, complement activation, and acute phase reactant expression, which collectively lead to the breakdown of the BRB and compromised perfusion. ${ }^{22}$ These observations strongly suggest that DR may be an inflammatory or a parainflammatory disease, ${ }^{23}$ and it has been shown that such inflammatory cascades are accelerated by the upregulation of VEGF. ${ }^{24}$

Here, using an STZ-induced murine model of diabetes, we examined the protective effects of aflibercept against microvascular structural changes that occur in the early stage of DR, such as pericyte loss, hyperpermeability, perfusion blockage, and inflammation.

\section{RESEARCH DESIGN AND METHODS}

\section{Chemicals and reagents}

STZ and fluorescein isothiocyanate (FITC)-dextran were purchased from Sigma (St. Louis, Missouri, USA). Aflibercept (Regeneron, New York, USA) was provided by Bayer (Leverkusen, Germany).

\section{Animals}

Eight-week-old C57BL/6N male mice (22-25g) were obtained from Orient Bio (Seoul, Republic of Korea) and maintained at $24^{\circ} \mathrm{C} \pm 0.5^{\circ} \mathrm{C}$ under a 12-hour lightdark cycle. Because the present study sought to evaluate the potential therapies for the early pathology of DR, we adopted the STZ-induced rodent model of diabetes that presents the features of non-proliferative or early $\mathrm{DR}^{17}$ instead of the Kimba (trVEGF029) transgenic mouse model used for studying proliferative or advanced DR and the oxygen-induced retinopathy model for studying retinal neovascularization and non-perfusion. To generate the STZ-induced model of DR, mice were intraperitoneally injected with STZ $(150 \mathrm{mg} / \mathrm{kg}$ body weight in $50 \mathrm{mM}$ citrate buffer, $\mathrm{pH} 4.5$ ) after 4 hours of fasting; for control, mice were injected with citrate buffer alone. ${ }^{25}$ Mice with blood glucose levels greater than $300 \mathrm{mg} / \mathrm{dL}$ at 1 week after STZ injection were considered as having diabetes. Four weeks after the injection, mice were injected with either aflibercept $(25 \mathrm{mg} / \mathrm{kg})$ or saline intraperitoneally once a week for 4 weeks. ${ }^{26-32}$ Body weights and blood glucose levels were measured at intervals of 1 and 2 weeks, respectively. In total, 220 mice were sacrificed for the experiment. Animals were sacrificed at 8 weeks after STZ injection when the vascular changes were prominent, as described in our previous report. ${ }^{20}$

\section{Fundus photography and fluorescein angiography}

Fundus photography and fluorescein angiography were performed at 8 weeks after STZ injection using the Micron III retinal imaging system (Phoenix Research Laboratories, Pleasanton, California, USA) under 1.5\% isoflurane inhalation anesthesia. Images were captured using a contact lens in the Micron III system after intraperitoneal injection of $0.3 \mathrm{~mL}$ of $2 \%$ fluorescein sodium (Alcon Laboratories, Fort Worth, Texas, USA). Earlyphase images were obtained at $3 \mathrm{~min}$ after dye injection, whereas late-phase images were collected $15 \mathrm{~min}$ after 
injection. Image software (National Institutes of Health, Bethesda, Maryland, USA) was used for quantification of leakage intensity, and the values from five different measurements from vessels other than the main vessels were averaged.

\section{Cardiac perfusion and flat-mount retinal preparations}

Eight weeks after STZ injection, the mice were anesthetized by intramuscular injection of $0.3 \mathrm{~mL}$ of zoletil (diluted 1:5 with saline). After creating an incision in the chest to expose the heart, $0.5 \mathrm{~mL}$ of $15 \mathrm{mg} / \mathrm{mL}$ fluorescein-dextran (2000 kDa, Sigma) was injected into the left ventricle to evaluate retinal perfusion. After $5 \mathrm{~min}$, the eyes were harvested and fixed by incubating with $4 \%$ paraformaldehyde for 1 hour. With the same method, $0.5 \mathrm{~mL}$ of $50 \mu \mathrm{g} / \mathrm{mL}$ concanavalin $\mathrm{A}$ in $0.1 \mathrm{M}$ sodium bicarbonate (tetramethylrhodamine conjugate; Molecular Probes, Eugene, Oregon, USA) was injected into the left ventricle to visualize intravascular leukocyte recruitment. After ex vivo staining with either fluorescein-dextran or concanavalin A, the retinal tissues were dissected and flat-mounted on glass slides with coverslips. Photographs were taken with an LSM780 confocal microscope (Carl-Zeiss, Oberkochen, Germany).

\section{Immunohistochemistry}

Retinas were collected from enucleated eyes that had been fixed in $4 \%$ paraformaldehyde, washed in phosphate-buffered saline (PBS), and incubated with permeabilizing and blocking solution containing $0.5 \%$ Triton X-100\% and 1\% bovine serum albumin in PBS. The presence of retinal pericytes was evaluated by immunostaining with antibodies against platelet-derived growth factor receptor- $\beta$ (PDGFR- $\beta$, 1:100; Abcam, Cambridge, UK) at $4^{\circ} \mathrm{C}$ for 7 days. Retinal vessels were costained with an antibody against the endothelial cell marker, CD31 (1:100; Millipore, Bedford, Massachusetts, USA). Leukocyte recruitment was assessed by immunostaining with an antibody against the common leukocyte antigen, CD45 (1:100; Abcam). Primary antibodies were subsequently detected by incubation at $4^{\circ} \mathrm{C}$ for 1 day with the appropriate Alexa Fluor-conjugated secondary antibody (Alexa Fluor 555-donkey anti-rabbit IgG or Alexa Fluor 488goat anti-hamster IgG; Invitrogen, Carlsbad, California, USA) diluted at 1:250. Retinal tissue was also stained with Alexa Fluor 488-conjugated isolectin GS-IB 4 (Molecular Probes) that binds to perivascular and endothelial cells.

Retinal sections were prepared using a cryostat and placed on glass slides. After fixation in $4 \%$ paraformaldehyde, slide-mounted retinal sections were washed with PBS and incubated in a permeabilizing and blocking solution $(0.2 \%$ Triton $\mathrm{X}-100 \%$ and $1 \%$ bovine serum albumin in PBS). After incubation with anti-VEGF (1:200; Santa Cruz, Dallas, Texas, USA), antivascular cell adhesion molecule-1 (VCAM-1; 1:250; Abcam), and anti-intercellular adhesion molecule-1 (ICAM-1, 1:250; Abcam) at $4^{\circ} \mathrm{C}$ for 24 hours, the tissues were further incubated with Alexa Fluor-conjugated secondary antibodies
(1:500; Invitrogen) and examined using an LSM780 confocal microscope (Carl Zeiss).

\section{Quantification of pericytes and leukocytes}

Pericyte counts were determined from the averages obtained from five randomly selected areas in each eye. Leukocytes and aggregated leukocytes were counted using ImageJ software. Aggregated leukocytes were defined as cases in which multiple CD45-positive cells were attached to one another and occupied an area larger than 5 pixels.

\section{Western blot analysis}

Eyes were enucleated at 8 weeks after STZ injection, and western blot analyses were performed..$^{20}$ Pericytes and whole-eye tissues were lysed using radioimmunoprecipitation assay buffer $(20 \mathrm{mM}$ Tris-Cl pH 7.4, $150 \mathrm{mM}$ $\mathrm{NaCl}, 1 \mathrm{mM}$ EDTA, $1 \mathrm{mM}$ ethylene glycol tetraacetic acid, $1 \%$ Triton $\mathrm{X}-100,2.5 \mathrm{mM}$ sodium pyrophosphate, $1 \mu \mathrm{M} \mathrm{Na} \mathrm{VO}_{4}, 1 \mu \mathrm{g} / \mathrm{mL}$ leupeptin, and $1 \mathrm{mM}$ phenylmethylsulfonyl fluoride). Lysates were centrifuged and the protein concentrations in supernatants were determined using the detergent-compatible Protein Assay Reagent (BioRad, Hercules, California, USA). Samples containing equal amounts of protein were separated by sodium dodecyl sulfate-polyacrylamide gel electrophoresis and transferred to a polyvinylidene difluoride membrane (Millipore). Membranes were first incubated with primary antibodies overnight at $4^{\circ} \mathrm{C}$ and then with horseradish peroxidase-conjugated goat anti-rabbit IgG or anti-mouse IgG, as appropriate (1:5000; Pierce, Rockford, Illinois, USA). The primary antibodies used were anti-VEGF (1:500, Santa Cruz) and anti- $\beta$-actin (1:2500, Sigma). Protein band intensities were quantified by densitometry using ImageJ software.

\section{Statistical analysis}

All results are presented as mean $\pm \mathrm{SE}$ of the mean. Student's t-test was used to evaluate the significance of differences between two groups, and one-way analysis of variance with post hoc analysis using Bonferroni correction was used to evaluate the significance of differences among three or more groups. Values of $<0.05$ were considered statistically significant. All statistical analyses and graphical presentations were conducted using the Sigma Plot V.10.0 software (Systat Software, San Jose, California, USA).

\section{RESULTS}

\section{Changes in body weight and blood glucose level}

The body weight and blood glucose level of mice were measured for 8 weeks following injection with normal saline (vehicle) or STZ. Whereas vehicle-injected control mice maintained normoglycemia and gained weight $(\sim 6 \mathrm{~g})$ over this period, STZ-induced mice with diabetes were markedly hyperglycemic and failed to gain weight. Aflibercept treatment did not significantly affect the changes in glucose level or body weight in both vehicle 
A

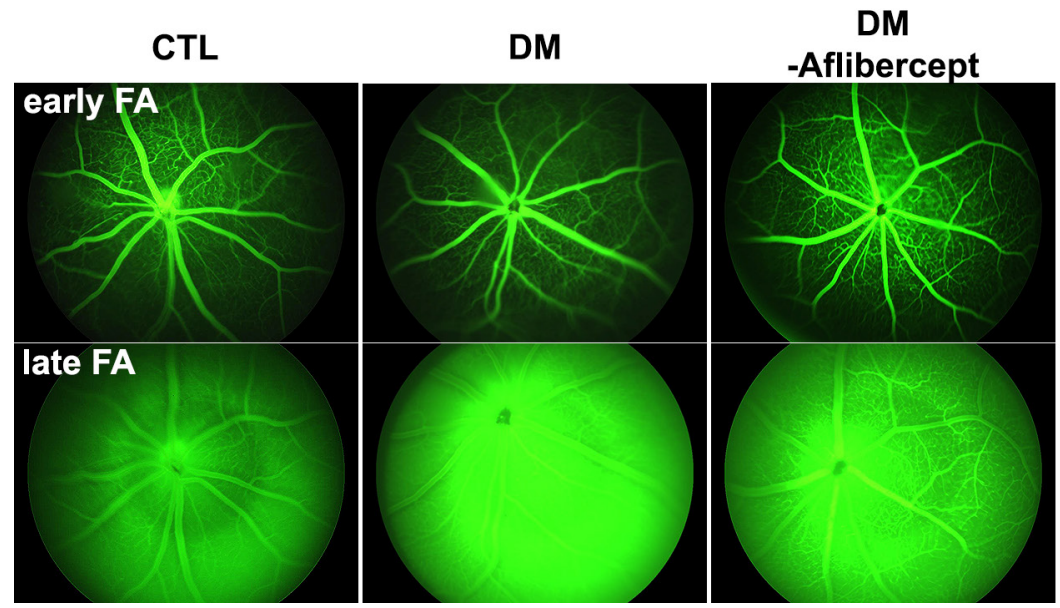

B

Figure 1 Representative images and fluorescein angiography of mice with diabetes at 8 weeks after the induction of diabetes. (A) Early phase was taken at $3 \mathrm{~min}$, and late phase was taken at $15 \mathrm{~min}$ after fluorescein injection. All images were obtained in the same light exposure condition. Fluorescein staining intensity was greater in the late stage in mice with diabetes (DM, $n=12$ ) than in CTL mice $(n=16)$. Treatment with aflibercept in mice with diabetes (DM-aflibercept, $n=11)$ reduced leakage compared with that in untreated mice with diabetes. (B) Quantification of fluorescein angiography results. Differences in intensity between late and early stages were averaged from five separate fields. ${ }^{*} \mathrm{P}<0.05,{ }^{\#} \mathrm{P}<0.001$. CTL, control; DM, diabetes mellitus.

and mice with diabetes (online supplemental figure S1). Because the data on blood glucose, body weight, and other experimental results were not significantly different between the aflibercept-treated control mice and the vehicle-treated control mice, the control data were presented as a single group for simplified data presentation.

\section{Changes in retinal vascular permeability in STZ-induced mice with diabetes}

To determine whether the STZ animal model successfully recapitulated the salient features of DR, including the disruption of BRB leading to the leakage of fluid through the loose capillary wall, we non-invasively examined the changes in retinal vasculature structure and permeability using fundus photography and fluorescein angiography at 8 weeks after STZ injection. Compared with control mice without diabetes, mice with diabetes showed more leakage of the fluorescein dye, defined as increased blurring and reflecting due to the presence of fluorescein in the vitreous cavity, especially in the late phase $(15 \mathrm{~min}$ after fluorescein injection). In mice with diabetes treated with aflibercept, the degree of fluorescein leakage was lower than that in mice with diabetes without aflibercept treatment (figure 1).

\section{Peripheral perfusion block and leukocyte recruitment in the diabetic mouse retina}

Next, retinal perfusion was examined in flat-mounted retinas using the FITC cardiac perfusion method (figure 2A,C). While normal perfusion was maintained to the very edge of the peripheral retina in control mice, hypoperfusion became conspicuous in the periphery of diabetic mouse retinas at 6-8 weeks after STZ injection. Interestingly, leukocytes (ie, cells positive for the common leukocyte antigen $\mathrm{CD} 45$ ) were recruited to the peripheral retinal tissue during the same period (figure 2B,D) and not in the central area where the perfusion was intact. Under higher magnification (figure 2E), recruited leukocytes were found mainly at the margins of retinal capillary perfusion. $\mathrm{CD} 45^{+}$cells showed a tendency to form large cell clumps at 8 weeks. When counting $\mathrm{CD} 45^{+}$cells, large cell clumps were counted as single cells because counting the exact number of overlapping cells in each clump was not feasible; as a result, we observed that the number of CD $45^{+}$cells was decreased at 8 weeks, whereas an abundant amount recruited leukocytes was observed. Hence, aggregated leukocytes or leukocyte clumps were counted again separately. Aggregated leukocytes, defined as large leukocyte-stained areas covering more than five square pixels, were significantly increased in mice with diabetes, consistent with the possibility that leukocyte aggregation inside capillaries is responsible for blocking the blood flow within capillaries (figure 2F).

\section{Changes in the expression of VEGF and adhesion molecules in} the diabetic retina

Under certain circumstances, VEGF acts as a proinflammatory factor and recruits leukocytes, especially in the context of DR. ${ }^{33}$ We thus first examined whether VEGF levels were increased in the diabetic retina and whether aflibercept affected the elevated VEGF levels. Western blot analyses showed that VEGF was upregulated in mice with diabetes, an effect that was attenuated by aflibercept treatment (figure 3A,B); this VEGF-reducing effect of aflibercept was more prominent for the dimeric form of VEGF than for the monomeric form.

In immunohistochemically stained retinal cross sections, upregulation of VEGF was observed predominantly in the inner nuclear layer and the ganglion cell layer, which are where deep capillary vessels-the main 
A

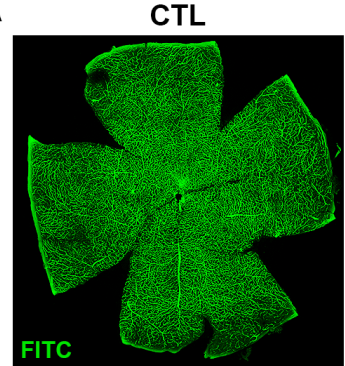

B

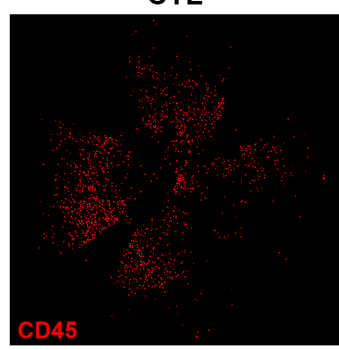

C

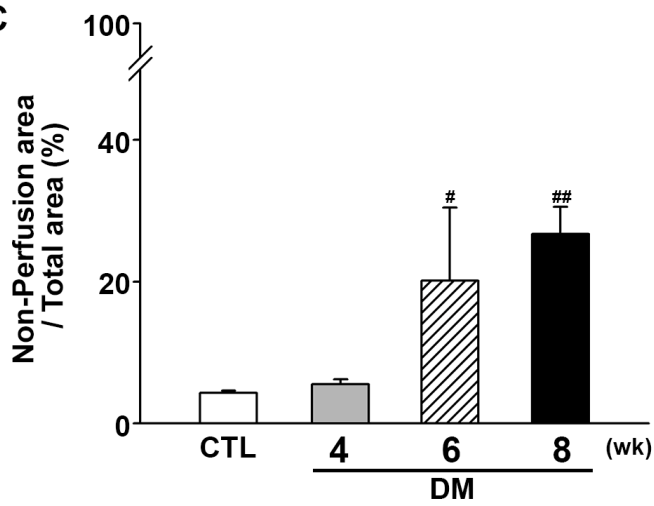

E

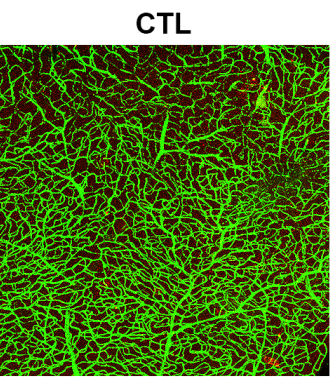

$4 w k$

4wk
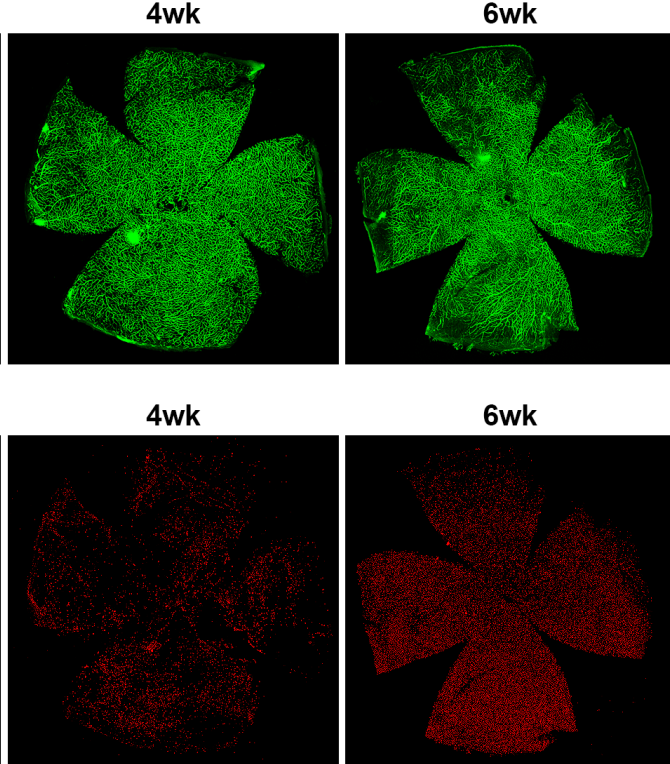

$6 w k$
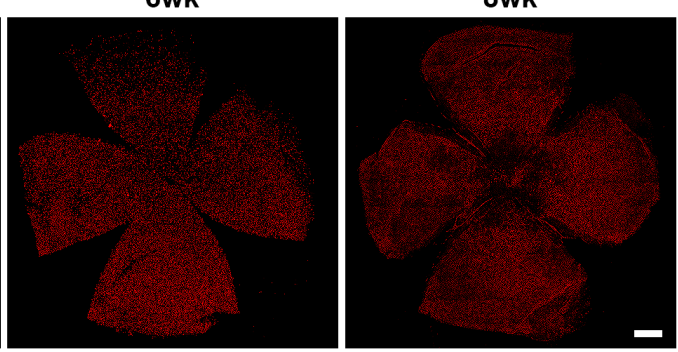

D

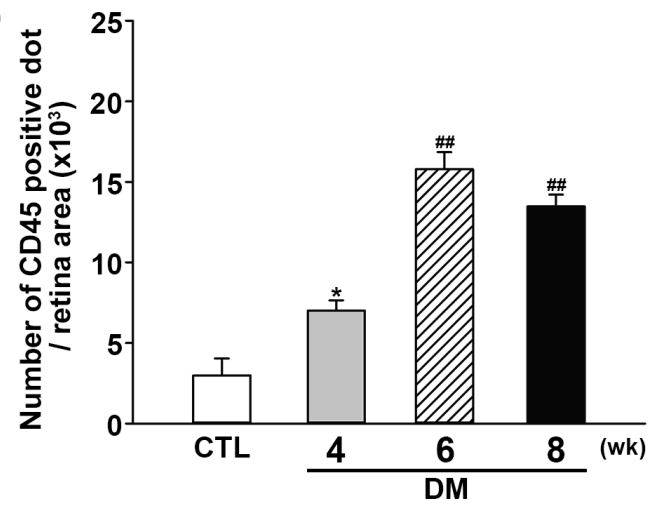

$\mathbf{F}$

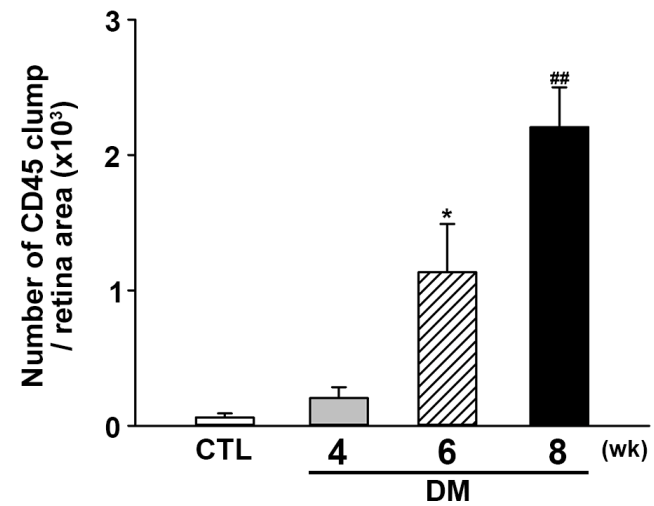

Figure 2 Changes in retinal perfusion and leukocyte accumulation. (A) Representative fluorescein angiographic images of retinal flat mounts showing retinal perfusion in CTL mice, and changes in perfusion 4, 6, and 8 weeks after diabetic induction with STZ injection. Perfusion decreased beginning at 6 weeks after STZ injection and was significantly lower at 8 weeks compared with CTL mice. Original magnification: $\times 200$; scale bar: $500 \mu \mathrm{m}$. (B) Representative images of flat-mount retinas immunostained for CD45 to assess leukocyte accumulation at 4, 6, and 8 weeks after diabetic induction with STZ injection compared with CTL mice. Retinal leukocyte recruitment increased as the perfusion block progressed. Original magnification: $\times 200$; scale bar: $500 \mu \mathrm{m}$. (C) Quantitative analysis of retinal non-perfusion showing that hypoperfusion became prominent beginning at 6 weeks after STZ injection (CTL, $n=14 ; D M, 4$ weeks, $n=3 ; 6$ weeks, $n=3 ; 8$ weeks, $n=13 ;{ }^{\#} p<0.005$, ${ }^{\#} p<0.001$ compared with $\mathrm{CTL}$ ). (D) Quantitative analysis showing that retinal $\mathrm{CD} 45^{+}$dots were increased as non-perfusion progressed (CTL, $n=4$; DM, 4 weeks, $n=4 ; 6$ weeks, $n=3 ; 8$ weeks $n=6 ;{ }^{*} p<0.05$, ${ }^{\#} p<0.001$ compared with CTL). (E) Leukocyte accumulation occurred mainly at the border of hypoperfusion, possibly providing the etiology of non-perfusion. Original magnification: $\times 200$; scale bar: $500 \mu \mathrm{m}$. (F) Aggregated leukocytes, defined as CD45-positive cells occupying an area larger than five pixels, were counted using ImageJ software. Leukocyte aggregation greatly increased as non-perfusion progressed (CTL, $n=4$; DM, 4 weeks, $n=4 ; 6$ weeks, $n=3 ; 8$ weeks $n=6 ;{ }^{*} p<0.05,{ }^{\# \#} p<0.001$ compared with CTL). CTL, control; DM, diabetes mellitus; FITC, fluorescein isothiocyanate; STZ, streptozotocin. 
A

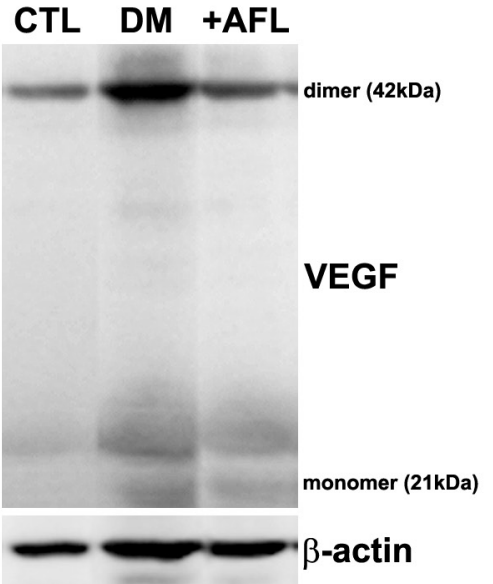

B

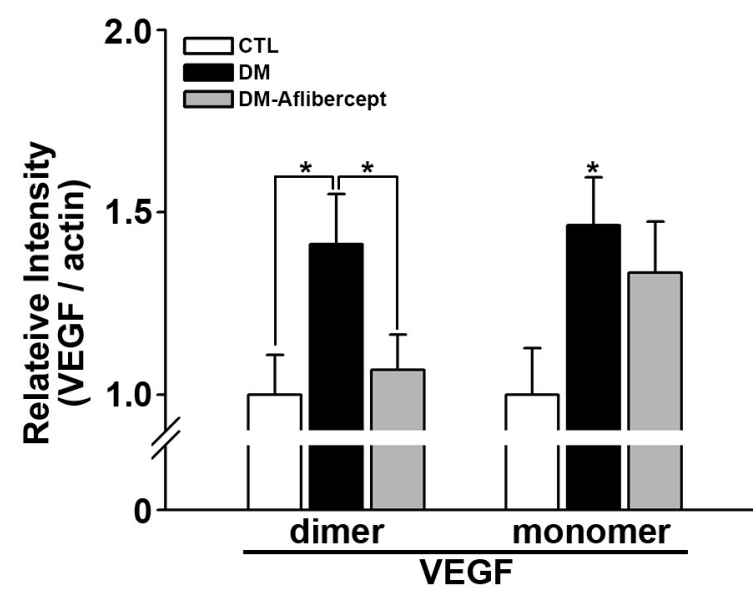

C

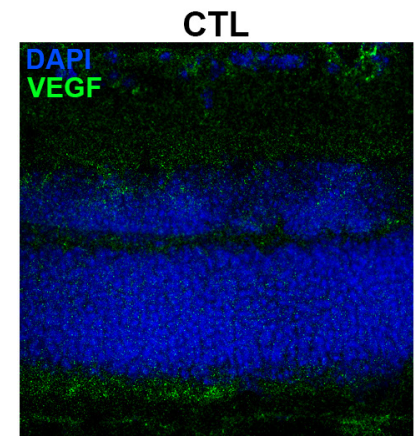

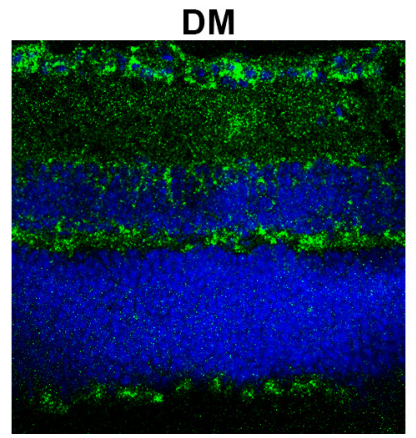

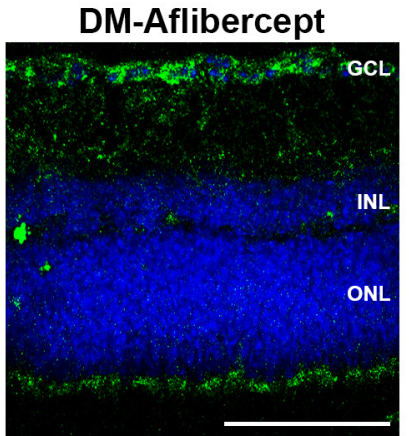

Figure 3 Changes in VEGF in the retinas of control mice, mice with diabetes, and AFL-treated mice with diabetes. (A) Representative images of western blots for CTL mice $(n=9)$, mice with diabetes (DM, $n=7)$, and AFL-treated mice with diabetes $(+\mathrm{AFL}, \mathrm{DM}-\mathrm{AFL} ; \mathrm{n}=8)$. (B) Both VEGF dimers and monomers were significantly increased in mice with diabetes compared with CTL mice. AFL treatment significantly decreased VEGF level, mainly in dimers ( $\left.{ }^{*} \mathrm{p}<0.05\right)$. (C) In retinal cross sections, VEGF upregulation was strongly observed in the GCL and INL regions, where superficial and deep capillary plexuses exist. VEGF expression was not observed in the avascular ONL. This change was attenuated by AFL treatment. Original magnification: $\times 400$; scale bar: 100 m. AFL, aflibercept; CTL, control; DM, diabetes mellitus; DAPI, 4',6-diamidino-2-phenylindole; GCL, ganglion cell layer; INL, inner nuclear layer; ONL, outer nuclear layer; VEGF, vascular endothelial growth factor.

vessels affected in DR-are located (figure 3C). Again, aflibercept treatment reduced the increases in VEGF in the diabetic retina, especially in the inner nuclear layer.

ICAM-1 and VCAM-1, the downstream molecules in the VEGF signaling pathway, play significant roles in the recruitment of leukocytes in the pathogenesis of DR. ${ }^{24} 34$ We thus examined the changes in ICAM-1 and VCAM-1 expression in the retina and found that similar to VEGF, both adhesion molecules were upregulated in mice with diabetes, and such increases were significantly inhibited by aflibercept treatment (online supplemental figure S2).

\section{Recovery of perfusion by aflibercept treatment in mice with diabetes}

Considering that aflibercept attenuated the downstream effects of VEGF signaling in the diabetic retina (ie, increased expression of ICAM-1 and VCAM-1), we next examined its effects on leukocyte recruitment and perfusion blockage. As shown in figure 4A,B, aflibercept reduced the peripheral perfusion blockage caused by diabetes, significantly decreasing the non-perfused area compared with that in mice with diabetes without aflibercept treatment. Leukocyte recruitment in the retinal periphery was also lower in aflibercept-treated mice with diabetes compared with that in control mice with diabetes without aflibercept treatment (figure 4C,D). Although CD45 staining was observed in leukocytes inside the capillary as well as those that had been extravasated, only the former could be expected to contribute to the blocking of the blood flow. Hence, we stained leukocytes ex vivo with concanavalin $\mathrm{A}$ and then reinjected them to allow exclusive visualization of leukocytes within the capillary lumen. Concanavalin A staining revealed an increase in concanavalin A-positive leukocytes in the diabetic retina, and this change was attenuated by aflibercept treatment (figure 5A). Costaining for isolectin showed that intravascular clumps of leukocytes indeed reduced perfusion by completely blocking multiple retinal capillaries, an effect that was again attenuated by aflibercept treatment (figure 5B). 
A
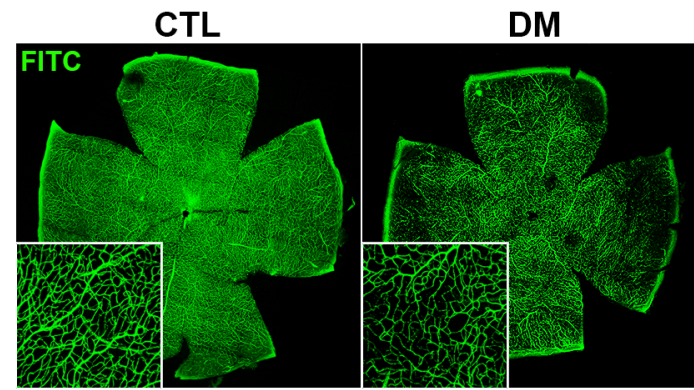

\section{DM-Aflibercept}

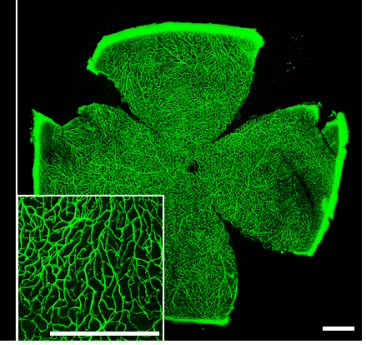

C

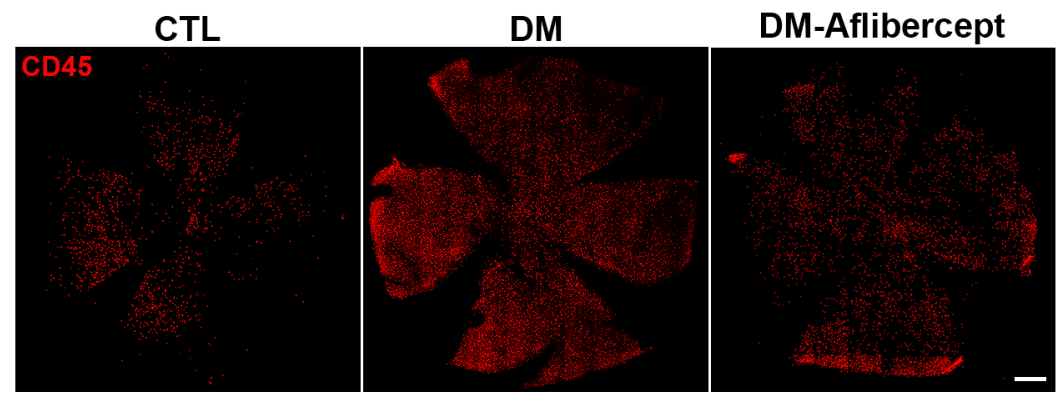

B

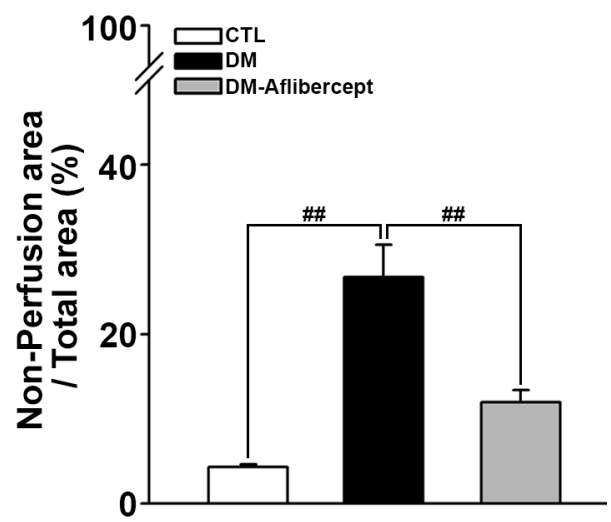

D

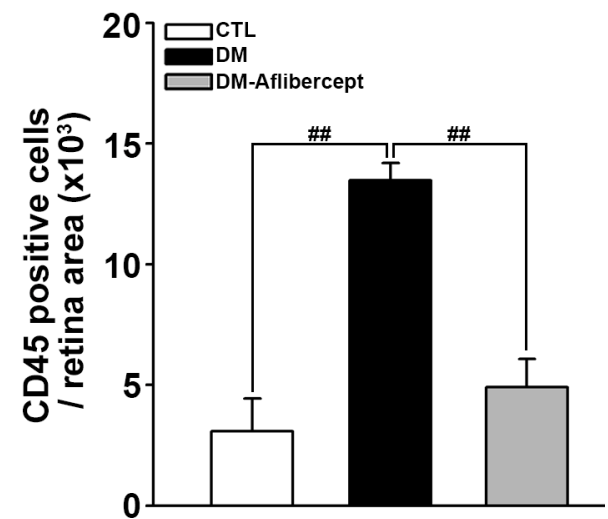

Figure 4 Aflibercept treatment ameliorates retinal hypoperfusion and reduces leukocyte recruitment in mice with diabetes. (A) Representative images of fluorescein angiograms of flat-mounted retinas of CTL, mice with diabetes (DM), and aflibercepttreated mice with diabetes (DM-aflibercept). Original magnification: $\times 200$; scale bar: $500 \mu m$. (B) Quantitation of non-perfused areas revealed that aflibercept treatment significantly reduced the non-perfused area compared with that in mice with diabetes (CTL, $n=14$; DM, $n=13$; DM-aflibercept, $n=21$; ${ }^{\# \#} \mathrm{p}<0.001$ ). (C) Representative images of flat-mounted retinas immunostained for CD45, a marker for leukocytes, in mice with diabetes with or without aflibercept treatment. Original magnification: $\times 200$; scale bar: $500 \mu \mathrm{m}$. (D) Recruited leukocytes were markedly increased in mice with diabetes compared with CTL mice, which was attenuated by aflibercept treatment (CTL, $n=4 ; D M, n=6$; DM-aflibercept, $n=6$; $\left.{ }^{\#} p<0.001\right)$. CTL, control; DM, diabetes mellitus; FITC, fluorescein isothiocyanate.

\section{Attenuation of pericyte loss with aflibercept treatment}

Finally, we examined the changes in vascular endothelial cells and pericytes in the retina. Retinal capillary endothelial cells constitute the capillary lumen, and retinal pericytes are crucial for the viability and regulation of endothelial cells. Although a perfusion blockage was observed in mice with diabetes, endothelial cell survival was maintained in this early diabetic mice model. However, retinal pericyte destruction was clearly detected in these mice, an effect that was attenuated by aflibercept treatment (figure 6). The whole retina images stained by PDGFR- $\beta$ and CD31 are presented in online supplemental figure S3.

\section{DISCUSSION}

The present study sought to examine the possibility that anti-VEGF treatment, which is widely used as a therapy for DME, might have therapeutic effects even against relatively early structural changes associated with DR, such as vascular leakage, perfusion blockage, inflammation, and pericyte loss. Using the STZ model of diabetes, we found that aflibercept, a potent anti-VEGF molecular trap, is highly effective in reducing these microvascular structural changes in DR. These results provide a possible explanation for the reduction in perfusion deficits shown in recent clinical trials ${ }^{101135}$ and raise the possibility that anti-VEGF treatment could be efficacious even in the earlier stage of DR when capillaries are not completely destroyed and the damage is still reversible.

The Diabetic Retinopathy Clinical Research Network Protocol S study showed that monthly intravitreal treatment with the anti-VEGF agent ranibizumab resulted in visual outcomes that were comparable to those with PRP, but with less development of neovascularization and the need for vitrectomy, ${ }^{9}$ thereby increasing interest in the clinical effects of anti-VEGF treatments on vascular structural changes and non-perfusion in DR. In a post hoc analysis of the VIVID/VISTA and RISE/RIDE studies, 
A
CTL
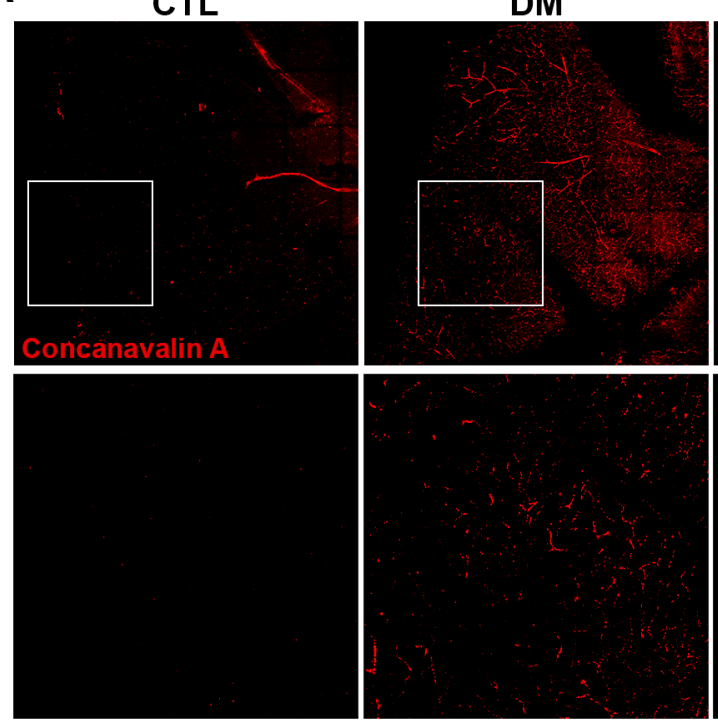

DM-Aflibercept
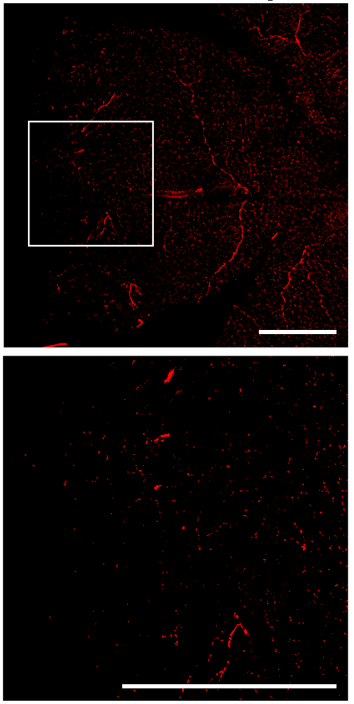

DM-Aflibercept

B

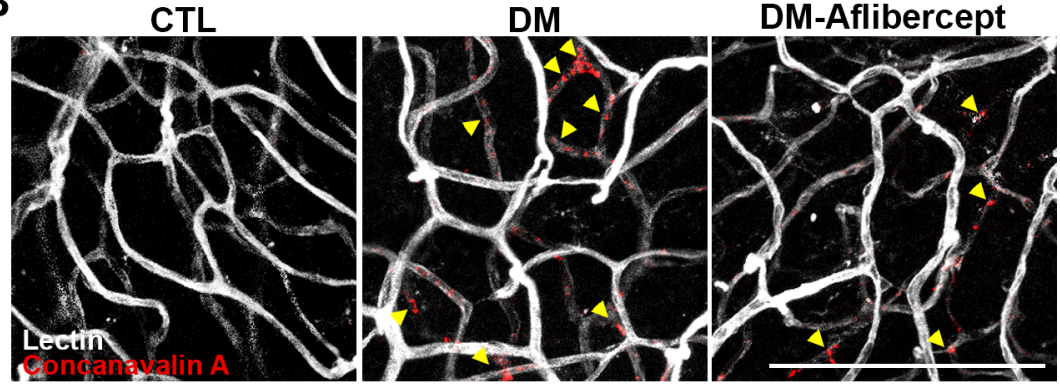

C

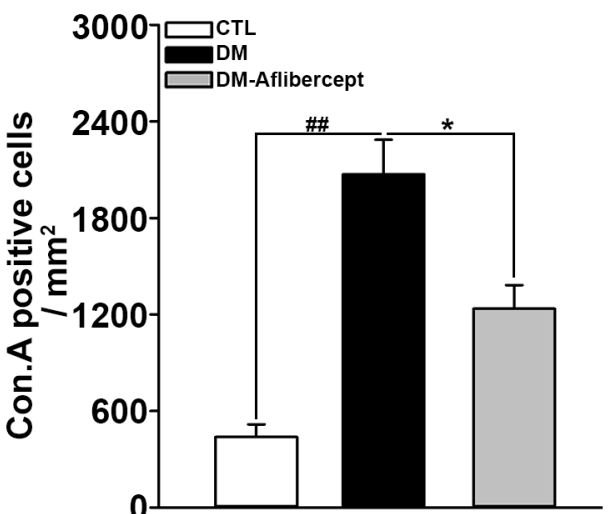

Figure 5 Accumulation of intravascular leukocytes in mice with diabetes. (A) Accumulated intravascular leukocytes were stained with concanavalin A. Intravascular-attached leukocytes were abundant in mice with diabetes (DM), but their numbers declined on aflibercept treatment $(C T L, n=3 ; D M, n=3$; DM-aflibercept, $n=4)$. Original magnification: $\times 200$; scale bar: $500 \mu m$ (B) Costaining with isolectin revealed that the concanavalin A-stained leukocytes were blocking the retinal capillary lumen. Arrowheads indicate the total luminal blockades caused by leukocyte aggregates. On aflibercept treatment, intravascular perfusion-blocking leukocytes were reduced. Original magnification: $\times 200$; scale bar: $100 \mu \mathrm{m}$. (C) Quantification of the number of concanavalin A-positive cells (CTL, $n=3$; DM, $n=3$; DM-aflibercept, $\left.n=4,{ }^{*} p<0.05,{ }^{\#} p<0.001\right)$. CTL, control; DM, diabetes mellitus.

which were designed to assess the viability of aflibercept and ranibizumab in the treatment of DME, anti-VEGF agents were associated with reduced progression of DRSS and reduced degree of macular non-perfusion in DR. ${ }^{10} 1135$ However, two other clinical trials, RECOVERY and CLARITY, failed to demonstrate significant improvements in non-perfusion in patients with PDR treated with aflibercept, although the zones of apparent reperfusion were detected in some patients. ${ }^{36} 37$ Discrepancies between these studies may reflect the fact that the latter 
A
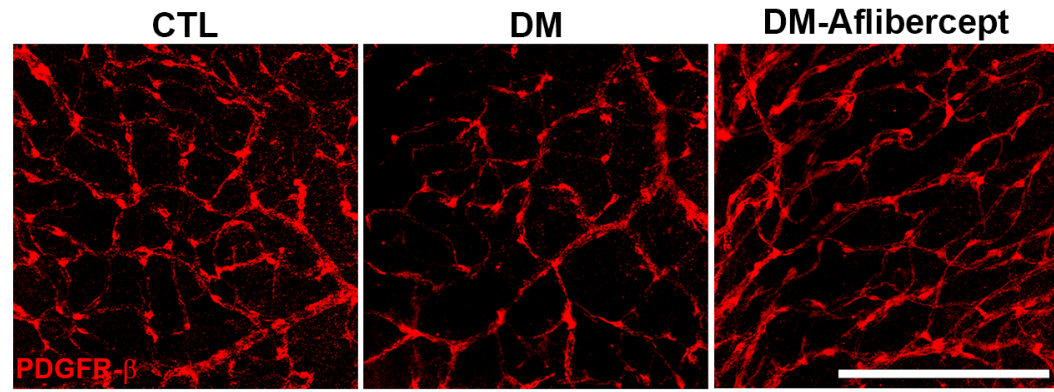

B

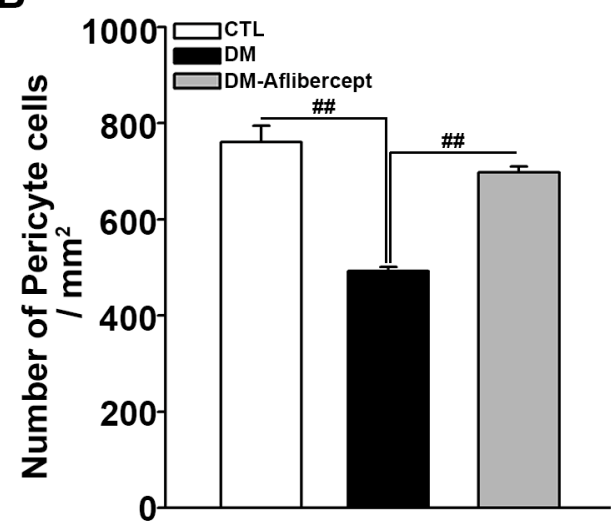

C
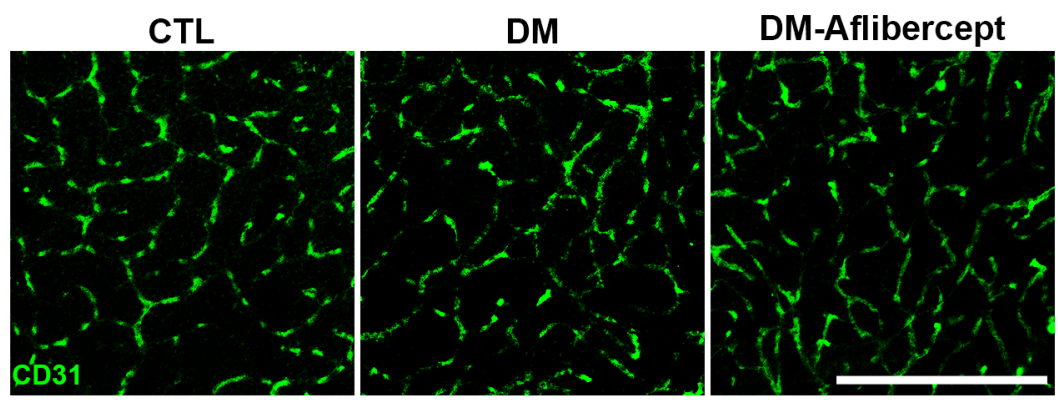

D

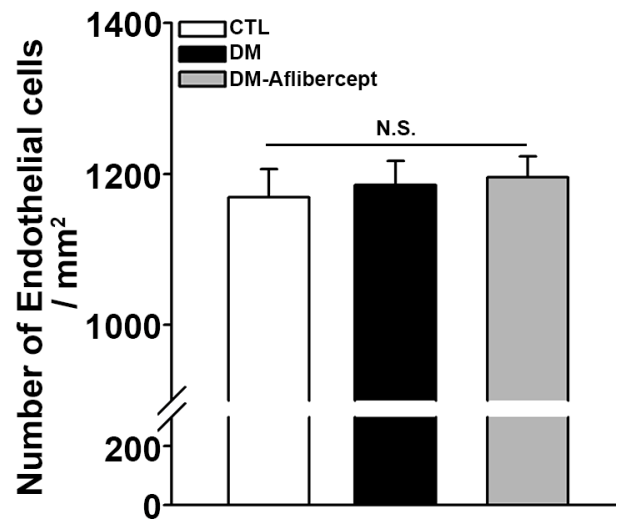

Figure 6 Attenuation of pericyte loss in the diabetic retina by aflibercept. (A) Representative images of PDGFR- $\beta$ staining for retinal pericytes. Pericyte numbers were decreased in mice with diabetes, and this decrease was attenuated by aflibercept treatment. Original magnification: $\times 200$; scale bar: $200 \mu \mathrm{m}$. (B) Quantification of the number of pericytes $(C T L, n=8$; $D M, n=15$; DM-aflibercept, $n=9$; $\left.{ }^{\#} \mathrm{p}<0.001\right)$. (C) Immunostaining of retinal flat mounts with antibodies for CD31. Endothelial cells were intact in mice with diabetes and showed no significant changes in aflibercept treatment. Original magnification: $\times 200$; scale bar: $200 \mu \mathrm{m}$. (D) Quantitative data of the number of endothelial cells (CTL, $n=3$; DM, n=3; DM-aflibercept, $n=4$; $p>0.05, N . S$.). CTL, control; DM, diabetes mellitus; N.S., not significant; PDGFR- $\beta$, platelet-derived growth factor receptor- $\beta$.

studies were performed mainly in the eyes of patients with PDR, which is an advanced stage of disease with irreversible retinal capillary destruction. In the present study, we tried to intervene in the process of diabetic perfusion block using aflibercept at an earlier stage of the disease when the retinal capillary endothelium was still intact (figure 6C). As a result, aflibercept was capable of reversing the perfusion deficit, along with the reduction of leukocyte aggregates and revitalization of pericytes. In a similar context, clinical data from our group showed that intervention with aflibercept at an earlier stage before advanced PDR reduced non-perfusion, thus highlighting the importance of intervening at an early stage of the disease in which capillaries are still viable. ${ }^{38}$

In the current study, we first examined the possibility that aflibercept treatment might affect hyperglycemia in STZ mice. If aflibercept ameliorated hyperglycemia, its beneficial effects could simply be a consequence of improved glucose levels. This proved not to be the case, as aflibercept did not significantly alter the blood glucose levels or cause changes in body weight in control or
STZ-treated mice. Because disruption of the BRB and leaky blood vessels are early pathogenic features of $\mathrm{DR},{ }^{1516}$ we next performed retinal angiograms to examine vessel leakage and found that fluorescein leakage was higher in mice with diabetes, which was successfully reduced on treatment with aflibercept. Notably, in VEGF assay, increases in VEGF levels in the inner nuclear layer where diabetic vascular changes mainly occur-and where capillary destruction in DME predominates ${ }^{39}$ - were specifically reduced by aflibercept treatment. Because deep capillary plexuses that lie in the inner nuclear layer supply oxygen to the photoreceptor, ${ }^{40}{ }^{41}$ this layer may be highly vulnerable to ischemia and thus prone to increases in VEGF expression under ischemic stress. This effect may explain how aflibercept reduces leakage in diabetic retinal blood vessels, a process that may be VEGF-dependent. ${ }^{8}{ }^{42}$ Quantitative analysis showed that the anti-VEGF reducing effect was more prominent in dimeric VEGF than in monomeric VEGF. VEGF normally binds to its receptors as a homodimer or heterodimer, and aflibercept binds the VEGF dimer on both sides of 
the dimer with a substantially stronger affinity compared with other anti-VEGF antibodies, ${ }^{43}$ which allows it to exhibit VEGF-binding stoichiometry and to form a stable and inert complex with VEGF. ${ }^{44}$ Thus, the structural design of aflibercept may explain its preferential effect on dimeric VEGF shown in the current study.

Another notable change in the DR model is inflammation, evidenced by the increase in leukocyte recruitment in vessels and the retina. ${ }^{22}$ Increased expression levels of adhesion molecules such as ICAM-1 and VCAM-1 in diabetes and their attenuation with aflibercept treatment are consistent with reports showing that these molecules are regulated by VEGF signaling. ${ }^{24} 34$ The density of recruited leukocytes was not the highest in the central area where the perfusion was intact-rather, the density was higher in the periphery where the perfusion reduced as time progressed. The far periphery, where the retinal perfusion was completely blocked, also showed CD $45^{+}$ cells, indicating that there were previous leukocyte infiltrations. Intriguingly, in high magnification images, leukocytes were abundantly observed at the margins of retinal capillary perfusion demarcated by FITC. However, we could not discern whether these $\mathrm{CD} 45^{+}$cells were intravascularly placed or extravasated in the retina tissue due to the staining method. Subsequent concanavalin A cardiac perfusion revealed that intravascular leukocytes clumps and aggregates were also increased in mice with diabetes, which may be a possible mechanism for the non-perfusion. Aflibercept treatment, which reduced the expression levels of ICAM-1 and VCAM-1, also decreased leukocyte recruitment as well as non-perfusion in the diabetic retina.

Pericytes are supporting cells that surround the retinal capillaries and actively communicate with adjacent endothelial cells, astrocytes, microglia, and neurons as part of a functional unit. ${ }^{45}$ The loss of pericytes leads to endothelial destabilization and result in BRB breakdown and hyperpermeability. Our results showed that pericyte loss in the diabetic retina was also attenuated by aflibercept treatment. We were unable to find direct evidence in the literature on the mechanism linking VEGF signaling and pericyte loss. Some studies reported that bovine retinal pericytes do not proliferate in response to VEGF, ${ }^{46}$ whereas others reported that VEGF caused a concentration-dependent increase in the loss of bovine pericytes. $^{48}{ }^{49}$ Greenberg et $a \tilde{l}^{0}$ reported that excessive VEGF expression induces the formation of VEGF receptor-2 (VEGFR-2)/PDGFR- $\beta$ heteromers, implying that abnormal receptor signaling may contribute to the suppression of pericyte function.

Aflibercept is able to target not only VEGF but also PIGF. Along with the changes in the VEGF level, the effects of aflibercept on PlGF can be linked to the attenuation of pericyte loss in mice with diabetes. In combination with the activity of VEGF on VEGFR-1 and VEGFR-2, PIGF plays a role in recruiting proangiogenic cells by stimulating VEGFR-1 ${ }^{51}$ Furthermore, the inhibition of PIGF or VEGFR-1 leads to the improvement of pericyte survival, indicating that pericyte loss is mediated by VEGFR-1 signaling. ${ }^{52-54}$ The effect of aflibercept on reducing both VEGF and PIGF may explain pericyte survival improvement via the VEGFR-1 signaling pathway in the murine model of early-stage DR.

One of the fundamental questions in DR is what triggers VEGF upregulation. The most likely candidates are high-glucose concentration and consequent upregulation of glycated macromolecules that trigger inflammation and VEGF upregulation. Once VEGF upregulation ensues, ICAM and VCAM are also upregulated, resulting in leukocyte stasis within the capillaries in the retinal periphery. Stasis and clumping of leukocyte may slow blood flow in the region and cause perfusion blockage. The block in perfusion then further increases VEGF expression, thereby establishing a positive feedback loop in DR. Our findings suggest that anti-VEGF treatment in the earlier stages of DR might interrupt this vicious cycle and help prevent its progression to advanced stages. Further studies on the potential efficacy of antiVEGF treatment for the early stages of DR are needed to confirm this possibility.

\section{Author affiliations}

${ }^{1}$ Department of Ophthalmology, Jeju National University Hospital, Jeju National University School of Medicine, Jeju, The Republic of Korea

${ }^{2}$ Neural Injury Research Center, Asan Institute for Life Sciences, Asan Medical Center, Seoul, The Republic of Korea

${ }^{3}$ Department of Neurology, Asan Medical Center, University of Ulsan College of Medicine, Seoul, The Republic of Korea

${ }^{4}$ Department of Ophthalmology, Asan Medical Center, University of Ulsan College of Medicine, Seoul, The Republic of Korea

Contributors EJS and JAC performed experiments and wrote the manuscript. YHY and J-YK coordinated the study, reviewed the manuscript and are the guarantors of this work; in this capacity, they had full access to all the data in the study and take responsibility for the integrity of the data and the accuracy of the data analysis.

Funding This study was supported by grants from Bayer Healthcare (IIR-KR2017-4533) and the Basic Science Research Program through the National Research Foundation of Korea (NRF) funded by the Ministry of Education (2017R1D1A1B05028221) and the Brain Research Program of the NRF funded by the Korean government (NRF-2017M3C7A1028949).

Competing interests None declared.

Patient consent for publication Not required.

Ethics approval The experimental protocols were approved (approval ID: IACUC 2018-13-020) by the Institutional Animal Care and Use Committee of Asan Institute for Life Sciences, Asan Medical Center, University of Ulsan College of Medicine (Seoul, Korea).

Provenance and peer review Not commissioned; externally peer reviewed.

Data availability statement All data relevant to the study are included in the article or uploaded as supplemental information.

Supplemental material This content has been supplied by the author(s). It has not been vetted by BMJ Publishing Group Limited (BMJ) and may not have been peer-reviewed. Any opinions or recommendations discussed are solely those of the author(s) and are not endorsed by BMJ. BMJ disclaims all liability and responsibility arising from any reliance placed on the content. Where the content includes any translated material, BMJ does not warrant the accuracy and reliability of the translations (including but not limited to local regulations, clinical guidelines, terminology, drug names and drug dosages), and is not responsible for any error and/or omissions arising from translation and adaptation or otherwise.

Open access This is an open access article distributed in accordance with the Creative Commons Attribution Non Commercial (CC BY-NC 4.0) license, which 
permits others to distribute, remix, adapt, build upon this work non-commercially, and license their derivative works on different terms, provided the original work is properly cited, appropriate credit is given, any changes made indicated, and the use is non-commercial. See: http://creativecommons.org/licenses/by-nc/4.0/.

\section{ORCID iDs}

Eoi Jong Seo http://orcid.org/0000-0001-6574-7744

Jae-Young Koh http://orcid.org/0000-0002-4318-495X

Young Hee Yoon http://orcid.org/0000-0002-2849-7528

\section{REFERENCES}

1 Lee R, Wong TY, Sabanayagam C. Epidemiology of diabetic retinopathy, diabetic macular edema and related vision loss. Eye Vis 2015;2:17.

2 Williams R, Airey M, Baxter $\mathrm{H}$, et al. Epidemiology of diabetic retinopathy and macular oedema: a systematic review. Eye 2004;18:963-83.

3 Lynch SK, Abràmoff MD. Diabetic retinopathy is a neurodegenerative disorder. Vision Res 2017:139:101-7.

4 Yau JWY, Rogers SL, Kawasaki R, et al. Global prevalence and major risk factors of diabetic retinopathy. Diabetes Care 2012;35:556-64.

5 Bandello F, Lattanzio R, Zucchiatti I, et al. Pathophysiology and treatment of diabetic retinopathy. Acta Diabetol 2013:50:1-20.

6 Wells JA, Glassman AR, Ayala AR, et al. Aflibercept, bevacizumab, or ranibizumab for diabetic macular edema: two-year results from a comparative effectiveness randomized clinical trial. Ophthalmology 2016;123:1351-9

7 Papadopoulos N, Martin J, Ruan Q, et al. Binding and neutralization of vascular endothelial growth factor (VEGF) and related ligands by VEGF trap, ranibizumab and bevacizumab. Angiogenesis 2012;15:171-85.

8 Heier JS, Korobelnik J-F, Brown DM, et al. Intravitreal aflibercept for diabetic macular edema: 148-week results from the VISTA and vivid studies. Ophthalmology 2016;123:2376-85.

9 Gross JG, Glassman AR, Browning D, et al. Panretinal photocoagulation vs intravitreous ranibizumab for proliferative diabetic retinopathy: a randomized clinical trial. JAMA 2015;314:2137-46.

10 Wykoff CC, Shah C, Dhoot D, et al. Longitudinal Retinal Perfusion Status in Eyes with Diabetic Macular Edema Receiving Intravitreal Aflibercept or Laser in VISTA Study. Ophthalmology 2019;126:1171-80.

11 Ip MS, Domalpally A, Hopkins JJ, et al. Long-Term effects of ranibizumab on diabetic retinopathy severity and progression. Arch Ophthalmol 2012;130:1145-52

12 Lazzara F, Fidilio A, Platania CBM, et al. Aflibercept regulates retinal inflammation elicited by high glucose via the PIGF/ERK pathway. Biochem Pharmacol 2019;168:341-51.

13 Platania CBM, Di Paola L, Leggio GM, et al. Molecular features of interaction between VEGFA and anti-angiogenic drugs used in retinal diseases: a computational approach. Front Pharmacol 2015;6:248.

14 Barber AJ, Baccouche B. Neurodegeneration in diabetic retinopathy: potential for novel therapies. Vision Res 2017;139:82-92.

15 Mizutani M, Kern TS, Lorenzi M. Accelerated death of retinal microvascular cells in human and experimental diabetic retinopathy. $J$ Clin Invest 1996;97:2883-90.

16 Ejaz S, Chekarova I, Ejaz A, et al. Importance of pericytes and mechanisms of pericyte loss during diabetes retinopathy. Diabetes Obes Metab 2008;10:53-63.

17 Lai AKW, Lo ACY. Animal models of diabetic retinopathy: summary and comparison. J Diabetes Res 2013;2013:106594.

18 Praidou A, Androudi S, Brazitikos P, et al. Angiogenic growth factors and their inhibitors in diabetic retinopathy. Curr Diabetes Rev 2010;6:304-12.

19 Fu D, Wu M, Zhang J, et al. Mechanisms of modified LDL-induced pericyte loss and retinal injury in diabetic retinopathy. Diabetologia 2012:55:3128-40.

20 Choi JA, Chung Y-R, Byun H-R, et al. The anti-ALS drug riluzole attenuates pericyte loss in the diabetic retinopathy of streptozotocintreated mice. Toxicol Appl Pharmacol 2017;315:80-9.

21 Chung Y-R, Choi JA, Koh J-Y, et al. Ursodeoxycholic acid attenuates endoplasmic reticulum stress-related retinal pericyte loss in streptozotocin-induced diabetic mice. J Diabetes Res 2017;2017:1763292

22 Joussen AM, Poulaki V, Le ML, et al. A central role for inflammation in the pathogenesis of diabetic retinopathy. Faseb $J$ 2004;18:1450-2.
23 Adamis AP, Berman AJ. Immunological mechanisms in the pathogenesis of diabetic retinopathy. Semin Immunopathol 2008;30:65-84

$24 \mathrm{Kim} \mathrm{I,} \mathrm{Moon} \mathrm{SO,} \mathrm{Kim} \mathrm{SH,} \mathrm{et} \mathrm{al.} \mathrm{Vascular} \mathrm{endothelial} \mathrm{growth} \mathrm{factor}$ expression of intercellular adhesion molecule 1 (ICAM-1), vascular cell adhesion molecule 1 (VCAM-1), and E-selectin through nuclear factor-kappa B activation in endothelial cells. J Biol Chem 2001;276:7614-20.

25 Furman BL. Streptozotocin-Induced diabetic models in mice and rats. Curr Protoc Pharmacol 2015;70:1-20.

26 Kim DY, Choi JA, Koh J-Y, et al. Efficacy and safety of aflibercept in in vitro and in vivo models of retinoblastoma. $J$ Exp Clin Cancer Res 2016;35:171.

27 Holash J, Davis S, Papadopoulos N, et al. VEGF-Trap: a VEGF blocker with potent antitumor effects. Proc Natl Acad Sci U S A 2002;99:11393-8.

28 Moroney JW, Sood AK, Coleman RL. Aflibercept in epithelial ovarian carcinoma. Future Oncol 2009:5:591-600.

29 Liu Y, Shen J, Fortmann SD, et al. Reversible retinal vessel closure from VEGF-induced leukocyte plugging. JCl Insight 2017;2:insight.95530.

30 Kim ES, Serur A, Huang J, et al. Potent VEGF blockade causes regression of coopted vessels in a model of neuroblastoma. Proc Natl Acad Sci U S A 2002;99:11399-404.

31 Eichten A, Adler AP, Cooper B, et al. Rapid decrease in tumor perfusion following VEGF blockade predicts long-term tumor growth inhibition in preclinical tumor models. Angiogenesis 2013;16:429-41.

32 Rudge JS, Holash J, Hylton D, et al. Vegf trap complex formation measures production rates of VEGF, providing a biomarker for predicting efficacious angiogenic blockade. Proc Natl Acad Sci U S A 2007:104:18363-70.

33 Reinders MEJ, Sho M, Izawa A, et al. Proinflammatory functions of vascular endothelial growth factor in alloimmunity. J Clin Invest 2003;112:1655-65.

34 Miyamoto K, Khosrof S, Bursell SE, et al. Vascular endothelial growth factor (VEGF)-induced retinal vascular permeability is mediated by intercellular adhesion molecule-1 (ICAM-1). Am J Pathol 2000;156:1733-9.

35 Reddy RK, Pieramici DJ, Gune S, et al. Efficacy of ranibizumab in eyes with diabetic macular edema and macular nonperfusion in ride and rise. Ophthalmology 2018;125:1568-74.

36 Nicholson L, Crosby-Nwaobi R, Vasconcelos JC, et al. Mechanistic evaluation of panretinal photocoagulation versus aflibercept in proliferative diabetic retinopathy: clarity substudy. Invest Ophthalmol Vis Sci 2018;59:4277-84.

37 Wykoff CC, Nittala MG, Zhou B, et al. Intravitreal aflibercept for retinal nonperfusion in proliferative diabetic retinopathy: outcomes from the randomized recovery trial. Ophthalmol Retina 2019;3:1076-86.

$38 \mathrm{Kim}$ YJ, Yeo JH, Son G, et al. The efficacy of intravitreal aflibercept injection in improvement of retinal nonperfusion in patients with diabetic retinopathy. [abstract] Invest Ophthalmol Vis Sci 2019;60:6545.

39 Lee J, Moon BG, Cho AR, et al. Optical coherence tomography angiography of DME and its association with anti-VEGF treatment response. Ophthalmology 2016;123:2368-75.

40 Birol G, Wang S, Budzynski E, et al. Oxygen distribution and consumption in the macaque retina. Am J Physiol Heart Circ Physiol 2007;293:H1696-704.

41 Wangsa-Wirawan ND, Linsenmeier RA. Retinal oxygen: fundamental and clinical aspects. Arch Ophthalmol 2003;121:547-57.

42 Niwa Y, Kakinoki M, Sawada T, et al. Ranibizumab and aflibercept: intraocular pharmacokinetics and their effects on aqueous VEGF level in vitrectomized and nonvitrectomized macaque eyes. Invest Ophthalmol Vis Sci 2015;56:6501-5.

43 Sarwar S, Bakbak B, Sadiq MA, et al. Fusion proteins: aflibercept (VEGF Trap-Eye). Dev Ophthalmol 2016;55:282-94.

44 MacDonald DA, Martin J, Muthusamy KK, et al. Aflibercept exhibits VEGF binding stoichiometry distinct from bevacizumab and does not support formation of immune-like complexes. Angiogenesis 2016;19:389-406.

45 Klaassen I, Van Noorden CJF, Schlingemann RO. Molecular basis of the inner blood-retinal barrier and its breakdown in diabetic macular edema and other pathological conditions. Prog Retin Eye Res 2013;34:19-48.

46 Ikuno $\mathrm{Y}$, Hibino $\mathrm{S}$, Bando $\mathrm{H}$, et al. Retinal glial cells stimulate microvascular pericyte proliferation via fibroblast growth factor and platelet-derived growth factor in vitro. Jpn J Ophthalmol 2002;46:413-8.

47 Nadal JA, Scicli GM, Carbini LA, et al. Angiotensin II stimulates migration of retinal microvascular pericytes: involvement of 
TGF-beta and PDGF-BB. Am J Physiol Heart Circ Physiol 2002;282:H739-48.

48 Grosskreutz CL, Anand-Apte B, Dupláa C, et al. Vascular endothelial growth factor-induced migration of vascular smooth muscle cells in vitro. Microvasc Res 1999;58:128-36.

49 Yamagishi S, Yonekura H, Yamamoto Y, et al. Vascular endothelial growth factor acts as a pericyte mitogen under hypoxic conditions. Lab Invest 1999;79:501-9.

50 Greenberg JI, Shields DJ, Barillas SG, et al. A role for VEGF as a negative regulator of pericyte function and vessel maturation. Nature 2008;456:809-13.

51 Carmeliet P, Moons L, Luttun A, et al. Synergism between vascular endothelial growth factor and placental growth factor contributes to angiogenesis and plasma extravasation in pathological conditions. Nat Med 2001;7:575-83.

52 Huang $\mathrm{H}, \mathrm{He} \mathrm{J}$, Johnson Da'Kuawn, et al. Deletion of placental growth factor prevents diabetic retinopathy and is associated with Akt activation and HIF1 $\alpha$-VEGF pathway inhibition. Diabetes 2015;64:200-12.

53 Van Bergen T, Etienne I, Cunningham F, et al. The role of placental growth factor (PIGF) and its receptor system in retinal vascular diseases. Prog Retin Eye Res 2019;69:116-36.

54 Cao R, Xue Y, Hedlund E-M, et al. VEGFR1-mediated pericyte ablation links VEGF and PIGF to cancer-associated retinopathy. Proc Natl Acad Sci U S A 2010;107:856-61. 